

\section{REVISTA \\ TEORÍA Y PRÁCTICA \\ DE LA \\ ARQUEOLOGÍA HISTÓRICA LATINOAMERICANA}

ISSN: 2250-866X (impreso) | ISSN: 2591-2801 (en línea)

AÑo VIII, VOLUMEN 8, PRIMAVERA DE 2019

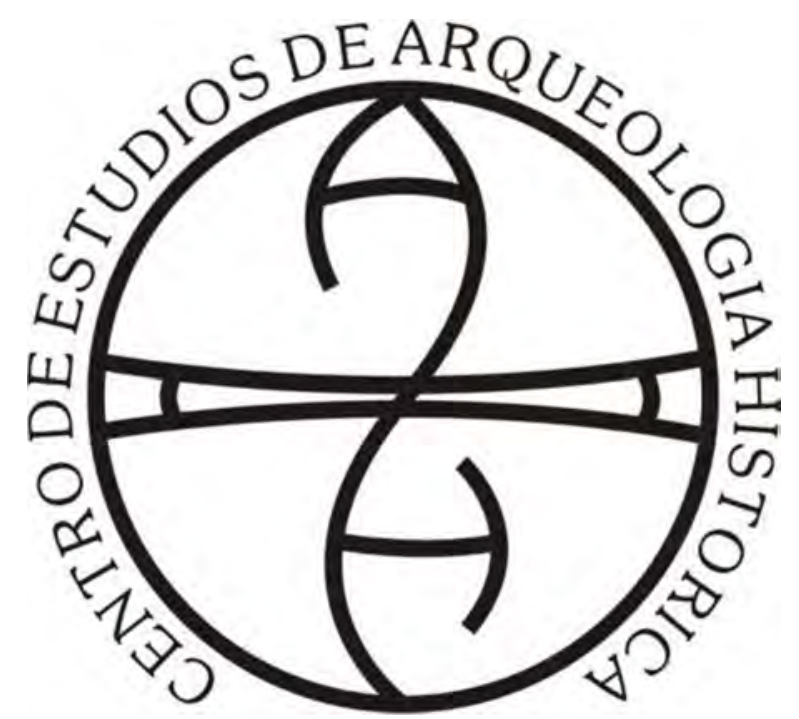

Centro de Estudios de Arqueología Histórica

FACULTAD DE HUMANIDADES Y ARTES | UNIVERSIDAD NACIONAL DE ROSARIO 
(Universidad Nacional de Rosario, Universidad Nacional de Río Cuarto,

Universidad Nacional de San Juan, Universidad de la República, Universidad Nacional de Trujillo)

\author{
AUTORIDADES DE LA UNIVERSIDAD NACIONAL DE ROSARIO \\ RECTOR: Lic. Franco Bartolacci \\ VICE-RECTOR: Od. Darío Macía \\ SECRETARIO GENERAL: Prof. José Goity \\ SECRETARIA ACADÉMICO Y DE APRENDIZAJE: Dr. Marcelo Vedrovnik \\ SECRETARÍA DE CIENCIA TECNOLOGÍA E INNOVACIÓN \\ PARA EL DESARROLLO: Ing. Guillermo Montero.
}

\author{
AUTORIDADES DE LA FACULTAD DE HUMANIDADES Y ARTES \\ DECANO: Prof. Alejandro Vila \\ VICEDECANA: Prof. Marta Varela \\ SECRETARIA ACADÉMICA: Dra. Marcela Coria
}

\author{
AUTORIDADES DEL CENTRO DE ARQUEOLOGÍA HISTÓRICA \\ DIRECTORA: Dra. Ana Rocchietti \\ SECRETARIA: Prof. Nélida de Grandis \\ PROSECRETARIA: Lic. Marianela Bizcaldi
}

DIRECTORAS - EDITORAS:

Dra. Ana Rocchietti y Prof. Nélida De Grandis

SECRETARIA DE EDICIÓN: Dra. Irene Dosztal

Este número es co-edición de las ponencias

del VIII Congreso Nacional de Arqueología Histórica (2018) entre:

Centro de Estudios en Arqueología Histórica: Directora Ana Rocchietti

Centro de Estudios en Arqueología Regional: Director Fernando Oliva

Centro de Estudios en Arqueología Subacuática: Directora Mónica Valentini

Departamento de Arqueología, Escuela de Antropología: Director Fernando Oliva
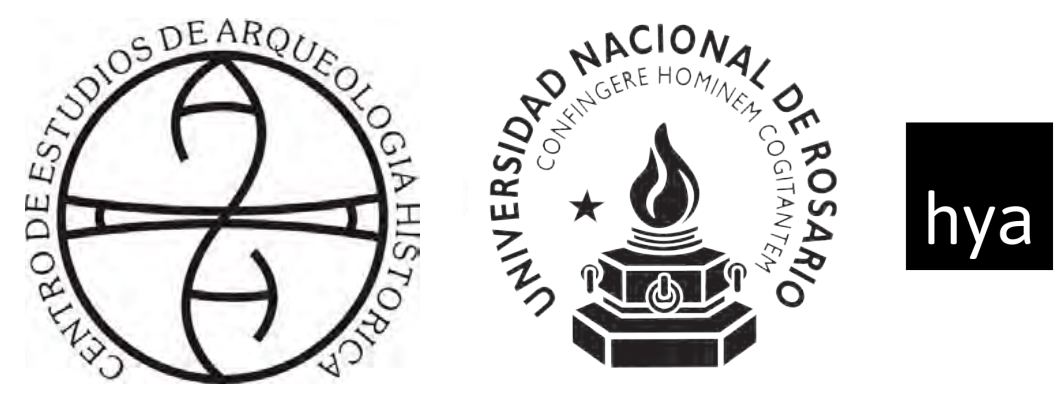

Facultad de Humanidades

y Artes_UNR
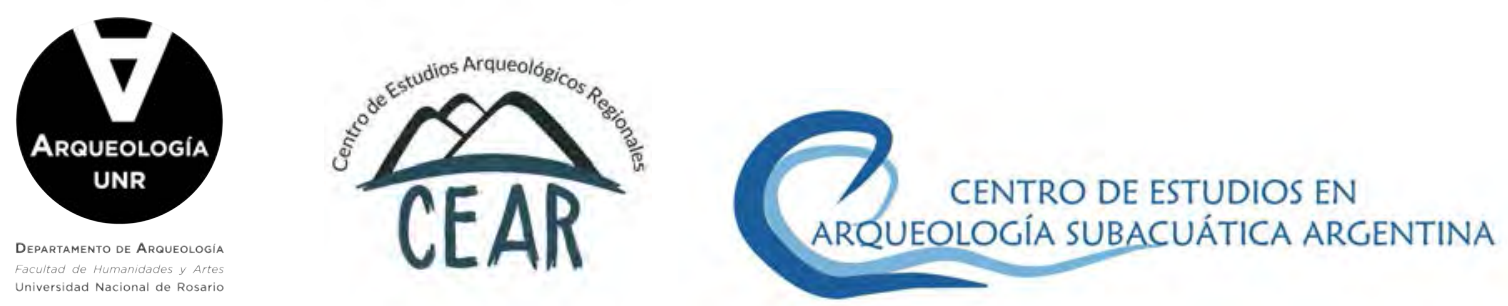
Comité Permanente de los Congresos Nacionales de Arqueología Histórica

Dr. Daniel Schávelzon (Universidad Nacional de

Buenos Aires)

Prof. María Teresa Carrara (Universidad Nacional de Rosario)

Prof. Carlos Baldassarre (Museo Municipal de Río

Grande, Tierra del Fuego) in memoriam

Dr. Mariano Ramos (Universidad Nacional de Luján, CONICET)

Dr. Horacio Chiavazza (Universidad Nacional de Cuyo)

Dra. Ana María Rocchietti (Universidad Nacional de

Rosario, Universidad Nacional de Río Cuarto)

Lic. Facundo Gómez Romero (Universidad Autónoma

de Barcelona)

\section{Comité Científico}

Dra. Tânia Andrade Lima (Universidade Federal do Rio de Janeiro)

Prof. Réginald Auger (CELAT/Département des

Sciences Historiques, Université Laval, Canadá)

Dr. Roberto Bárcena (Universidad Nacional de Cuyo, CONICET)

Dra. Marta Bonaudo (Universidad Nacional de Rosario, CONICET)

Dr. Leonel Cabrera (Universidad de la República, Uruguay)

Dr. Luis María Calvo (Universidad Católica de Santa

$\mathrm{Fe})$

Prof. Juan Castañeda Murga (Universidad Nacional de

Trujillo, Perú)

Dr. Carlos Ceruti (Museo de Ciencias Naturales y

Antropología "Prof. Antonio Serrano". Paraná)

Dr. Horacio Chiavazza (Universidad Nacional de Cuyo)

Dra. Silvia Cornero (Universidad Nacional de Rosario)

Prof. Pedro Paulo Funari (Universidade Estadual de

Campinas, Brasil)

Lic. Jorge A. Gamboa Velásquez (Universidad Nacional

Santiago Antuñez de Mayolo, Perú)

Dr. Eduardo Alejandro García (Universidad Nacional de

San Juan, CONICET)

Prof. Nélida De Grandis (Universidad Nacional de

Rosario)

Dr. Juan Bautista Leoni (Universidad Nacional de

Rosario, CONICET)

Dra. Amancay Martínez (Universidad Nacional de San

Luis)

Dra. Catalina Teresa Michieli (Universidad Nacional de

San Juan, CONICET)

Lic. Fernando Oliva (Universidad Nacional de Rosario)

Ing. Adrián Pifferetti (Universidad Tecnológica
Nacional Regional Rosario)

Dr. Mariano Ramos (Universidad Nacional de Luján, CONICET)

Dra. Ana María Rocchietti (Universidad Nacional de Rosario)

Dr. Daniel Schávelzon, (Universidad Nacional de Buenos

Aires, CONICET)

Dra. Carlota Sempé (Universidad Nacional de La Plata)

Dr. Mario Silveira (Universidad Nacional de Buenos Aires)

Dra. Silvia Simonassi (Universidad Nacional de Rosario)

Dra. Alicia Tapia (Universidad Nacional de Buenos Aires, Universidad Nacional de Luján)

Lic. Mónica P. Valentini (Universidad Nacional de Rosario)

Agrim. Benito Vicioso (Universidad Nacional de Rosario)

\section{Evaluaron este volumen}

Roberto Bárcena, María Teresa Boschin, Leonel Cabrera, Ulises Camino, María Rosa Carbonari, Carlos Ceruti, Horacio Chiavazza, Nicolás Ciarlo, Silvia Cornero, Eduardo Crivelli, Javier García Cano, Martín Gentinetta, María Laura Gili, Carlos Landa, Matilde Lanza, Melina Malandrino, Sebastián Pastor, Victoria Pedrotta, Josefina Piana,

Mercedes Podestá, Mariano Ramos, Daniel Schavelzon, Diana Tamburini, Mónica Therrien, Mónica Valentini y María Teresa Boschin

\section{Diseño y diagramación}

Eugenia Reboiro

(eugenia.reboiro@gmail.com)

\section{Curadoría}

Ana Rocchietti e Irene Dosztal

Foto de tapa: imagen del texto de Croce.

\section{Propietario responsable:}

Facultad de Humanidades y Artes, Universidad Nacional de Rosario Centro de Estudios de Arqueología Histórica

Entre Ríos 758. Rosario, provincia de Santa

Fe (2000). Argentina.

Telf.: +54 (0341) 4802670

E-mail: ceahunr@gmail.com

Decreto Ley 6422/57 de Publicaciones

Periódicas 


\section{Índice}

Editorial.

Arqueología histórica: programa de investigación y dimensiones epistemológicas...9 Ana María Rocchietti

De lozas, iglesias y machaqueños. Primeros pasos hacia una arqueología histórica en la cuenca norte del río desaguadero (La Paz, Bolivia).

Salvador Arano Romero

Identificación arqueológica de acciones militares en el campo de batalla de Cepeda, 1859.

Juan B. Leoni, Lucas H. Martínez, Cecilia Arias Morales, Daniela Cadenas,

Faustino Godoy, Mauro Ganem, María de la Paz Blanche y Héctor Meletta

Para una historia de la arqueología urbana en Buenos Aires (1848-1910) .59

Daniel Schávelzon y Francisco Girelli

Definiendo la cultura material colonial a partir de colecciones arqueológicas del Museo de La Plata.

Melina Bednarz, Julieta Penesis y Ana Igareta

La tangibilidad del conflicto: Arqueología del presente en las fronteras del norte santafesino....

Paula Del Río y Silvia Cornero

Arqueología histórica: evidencia material en el paisaje del establecimiento jesuita "La saladilla” (quebrada de Saladillo, La Rioja, Argentina). Juan Carlos Giuliano, Maira Ayelén Carrizo y María Soledad Gheggi

Graffiti ¿evidencia arqueológica o acto vandálico?. Camila Oliva

Arqueología histórica de los sistemas hidráulicos de la Hacienda

Jalpa de Cánovas, Guanajuato, México, y su relación con el sistema-mundo, Siglos XVIII-XIX

José Alberto Aguirre Anaya y Edgar Quispe Pastrana 
Paseo del bajo: una trinchera en la historia de Buenos Aires.................................143 Federico Martín Croce

Diferentes concepciones del patrimonio y su aplicación a la Casa Histórica de Tucumán también llamada Casa de la Independencia........................................155 Guillermo Etchevers

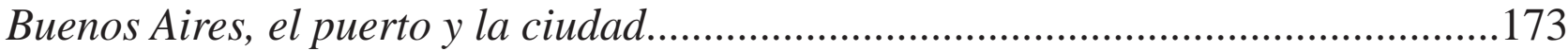
Mónica P. Valentini y Javier García Cano 


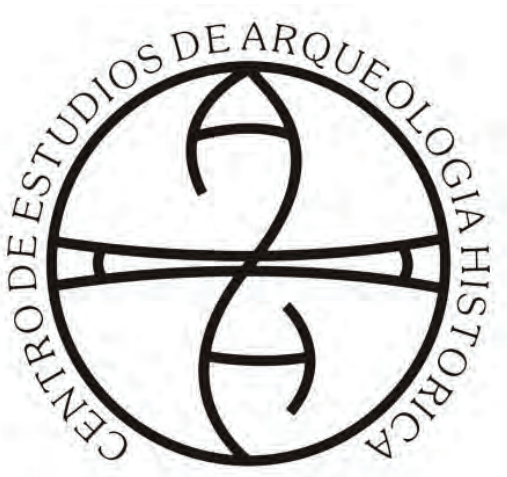

Centro de Estudios de Arqueología Histórica

Universidad Nacional de Rosario
Teoría y Práctica de la Arqueología Histórica

Latinoamericana | Año VIII. Vol. 8 | 2019

Revista del Centro de Estudios de Arqueología

Histórica, Facultad de Humanidades y Artes,

Universidad Nacional de Rosario

https://teoriaypracticaah.unr.edu.ar/index.php/index ceahunr@gmail.com

ISSN en línea: 2591-2801

ISSN versión impresa: 2250-866X

\title{
ArqueOLOGÍA histórica de los SISTEMAS HIDRÁUlicos DE LA HACIENDA JALPA DE CÁNOVAS, GUANAJUATO, MÉXICO, Y SU RELACIÓN CON EL SISTEMA-MUNDO, SIGLOS XVIII-XIX
}

\author{
José Alberto Aguirre Anaya* y Edgar Quispe Pastrana**
}

\section{Resumen}

El trabajo analiza cómo los sistemas hidráulicos que se construyeron a partir del siglo XVIII, convirtieron a las haciendas de la región del Bajío en los mayores productores de cereales que abastecieron de alimentos a las principales urbes novohispanas y a los centros argentíferos adyacentes a la región. Así, el Bajío fue reconocido como el "granero de la Nueva España” y a la vez por mantener a las zonas mineras de Guanajuato, Zacatecas y San Luis Potosí, además de articularse con otras actividades económicas, permitió al virreinato novohispano convertirse en el centro económico de la Corona y a través de ella se consolidó el sistema-mundo de la época. La plata mexicana se difundió a través del comercio por el mundo occidental y oriental; de esta forma se ha planteado que el peso novohispano reguló parte de la economía mundial.

Sin embargo, esta prosperidad productiva se vio paralizada desde 1810 cuando la región del Bajío se convirtió en el epicentro de la lucha independentista. Posteriormente, establecida la nueva nación mexicana las unidades productivas volvieron a activarse; sin embargo, las haciendas y las minas no volvieron a recuperar sus altas producciones.

Para el caso de la hacienda de Jalpa, Guanajuato, México, la temporalidad de estudio comprende desde 1750 hasta 1931, y comprende los tres momentos históricos de México. Es decir, se inicia cuando se construyó la presa vieja de Jalpa y de ahí en adelante se continuó con una serie de sistemas hidráulicos que convirtieron a la hacienda en una de las principales unidades agropecuarias y que tuvo su fin con la desmembración territorial de la propiedad.

Para abordar este trabajo se ha recurrido la arqueología histórica como metodología de trabajo, es decir hemos combinado elementos de la arqueología y la historia (Orser, 2007: 13). En nuestro caso de estu-

* Profesor investigador del Centro de Estudios Arqueológicos de El Colegio de Michoacán A.C., México.

** Becario del CONACYT en el Doctorado de Ciencias Sociales de El Colegio de Michoacán A.C., México. 
Teoría y Práctica de la Arqueología Histórica Latinoamericana | Año VIII. Vol. 8 | 2019

ISSN en línea: 2591-2801 | ISSN versión impresa: 2250-866X

dio se ha realizado una prospección de superficie que ha permitido identificar la cultura material; así se pudo reconstruir el sistema hidráulico de la hacienda, a la vez apoyado con documentos de archivo y de su interpretación de los procesos sociales hizo posible comprender la organización social que puso en marcha la unidad productiva.1 Por otro lado, con el enfoque de la ecología cultural (Steward, 1955: 37) se ha podido comprender el proceso adaptativo social a las condiciones naturales del entorno y al aprovechamiento de los recursos con fines económicos. Otro enfoque teórico importante es el sistema-mundo (Wallerstein, 1979). A partir del siglo XVI el mundo se hizo global como consecuencia del surgimiento del sistema capitalista en Europa, basado inicialmente en el comercio.

Palabras clave: El Bajío, Hacienda Jalpa de Cánovas, Sistemas hidráulicos, Arqueología histórica, Sistema-Mundo

\section{Abstract}

The work analyzes how the hydraulic systems that were built from the eighteenth century, turned the haciendas of the Bajío region into the largest cereal producers that supplied food to the main cities of New Spain and the argentiferous centers adjacent to the region. Thus, the Bajío was recognized as the New Spain barn and at the same time for maintaining the mining areas of Guanajuato, Zacatecas and San Luis Potosí, in addition to articulating with other economic activities, It allowed the New Hispanic viceroyalty to become the economic center of the Crown and through it the world-system of the time was consolidated. Mexican silver spread through trade throughout the Western and Eastern world; In this way it has been proposed that the New Hispanic peso regulated part of the world economy.

Sin embargo, esta prosperidad productiva se vio paralizada desde 1810 cuando la región del Bajío se convirtió en el epicentro de la lucha independentista. Posteriormente, establecida la nueva nación mexicana las unidades productivas volvieron a activarse; sin embargo, las haciendas y las minas no volvieron a recuperar sus altas producciones.

Para el caso de la hacienda de Jalpa, Guanajuato, México, la temporalidad de estudio comprende desde 1750 hasta 1931, y comprende los tres momentos históricos de México. Es decir, se inicia cuando se construyó la presa vieja de Jalpa y de ahí en adelante se continuó con una serie de sistemas hidráulicos que convirtieron a la hacienda en una de las principales unidades agropecuarias y que tuvo su fin con la desmembración territorial de la propiedad.

However, this productive prosperity was paralysed since 1810 when the Bajio region became the epicentre of the independence struggle. Later, established the new Mexican nation the productive units were reactivated; however, the haciendas and mines did not recover their high production. In the case of the hacienda of Jalpa, Guanajuato, Mexico, the study temporality extends from 1750 to 1931, and includes the three historical moments of Mexico. That is to say, it began when the old dam of Jalpa was built and from there on it was continued with a series of hydraulic systems that turned the farm into one of the main agricultural units and that had its end with the territorial dismemberment of property.

Historical archaeology has been used as a working methodology to address this work, that is, we have combined elements of archaeology and history (Orser, 2007: 13). In our case study, a surface survey has been carried out that has made it possible to identify the material culture; thus the hydraulic system of the farm could be reconstructed, at the same time supported by archival documents and their interpretation of social processes made it possible to understand the social organization that launched the productive unit. On the other hand, with the approach of cultural ecology (Steward, 1955: 37), it has been possible to understand the social adaptive process to the natural conditions of the environment and the use of resources for economic purposes. Another important theoretical approach. 
Teoría y Práctica de la Arqueología Histórica Latinoamericana | Año VIII. Vol. 8 | 2019

ISSN en línea: 2591-2801 | ISSN versión impresa: 2250-866X

Keywords: El Bajío, Hacienda Jalpa de Cánovas, Hydraulic systems, Arqueología histórica, SistemaMundo

\section{Introducción}

El Bajío es una región agrícola amplia que abarca parte de los Estados de Guanajuato, Jalisco, Michoacán y Querétaro. Se ubica en el centro-norte de México, cuya altitud comprende entre 1700-1800 m.s.n.m. A la vez, la región está rodeada de otras regiones adyacentes. Hacia el lado noroccidental se ubica la región de Los Altos de Jalisco, comprendida entre los 1800-2100 m.s.n.m; cuya actividad económica predominante fue la ganadería. En el lado nororiental se encontraba la región minera donde la explotación de la plata fue fundamental para el virreinato novohispano.

El territorio de la hacienda de Jalpa se extendía desde tierras del Bajío hasta las de los Altos de Jalisco. Su actividad económica fue mixta, se dedicaba a la agricultura y a la ganadería. A lo largo de su historia, las regiones atravesaron por fluctuaciones climáticas en los siglos XVI y XVII; estas situaciones provocaron sequías, y en consecuencia escasez de alimentos. Ante estos antecedentes, en el siglo XVIII, los hacendados se vieron obligados a tener una mejor comprensión de la naturaleza de la región y plantear soluciones acordes a dichas circunstancias para un mejor aprovechamiento de los recursos naturales, que finalmente se refleja en la apariencia del paisaje que hoy día se encuentra en la región. Esto conllevó a una adaptación social con el medio lo que permitió con el tiempo a una forma de identidad social del poblador abajeño.

A nivel interno, la hacienda desde 1750, empezó con la construcción de los sistemas hidráulicos lo que le permitió captar, almacenar y distribuir el agua para el regadío, principalmente para la producción de trigo. Las lluvias de temporal, que se presentan entre mayo a octubre, permitieron la producción del maíz y después de noviembre en adelante se aprovechaba las aguas captadas en presas o entarquinamientos para la siembra del trigo tan requerido en las urbes hispanas.

A nivel regional y en el contexto del virreinato novohispano del siglo XVIII, en el Bajío hubo un crecimiento demográfico y una mayor actividad no solo en la agricultura, la ganadería o la minería, sino también en otras actividades económicas. Así, en paralelo las molineras tuvieron mayor trabajo en el proceso de transformación de granos, se desarrolló el comercio y las manufacturas. Todas estas actividades se articularon y convirtieron al Bajío en el centro económico de la Nueva España, insertada en el Sistema-Mundo de entonces (Tutino, 2016; Wallerstein, 1979).

A través de este trabajo presentamos el desarrollo de la hacienda Jalpa de Cánovas como una muestra de lo que fueron las haciendas abajeñas. En 1708, la hacienda fue adquirida por Jerónimo Monterde y desde ese momento la propiedad estuvo en manos de la familia hasta 1865.

En este último año, Ignacia de Cevallos y Monterde y Antillón, falleció sin dejar descendencia, y dejó la propiedad a su esposo Manuel Cánovas, quien en segundas nupcias tuvo a su hija Guadalupe Cánovas. Ésta se casó con Oscar Braniff y ambos tendrían la hacienda hasta la Reforma Agraria.

Como ya lo hemos señalado, Jalpa también atravesó los periodos históricos que vivió México, aunque hay que aclarar que esta división refiere a procesos políticos: período virreinal novohispano 1519-1810; período independentista 1810-1821, y de 1822 a la actualidad corresponde a la república mexicana. En el caso de la historia rural de las haciendas tienen otro desarrollo temporal. Esto es más notorio en el proceso de independencia, porque mientras políticamente se señala una cierta cantidad de años, la vida de las haciendas, por su objetivo productivo, tuvo que empezar antes. Así, a través de las fuentes escritas se ha determinado que desde 1816 la hacienda Jalpa empezó a retomar sus actividades 
Teoría y Práctica de la Arqueología Histórica Latinoamericana | Año VIII. Vol. 8 | 2019

ISSN en línea: 2591-2801 | ISSN versión impresa: 2250-866X

productivas, aún a costa de condiciones difíciles por la ocupación militar, tanto de las fuerzas realistas como insurgentes, ya que la hacienda se encontraba dentro del escenario de las luchas independentistas en el Bajío. Superada esta etapa, se estableció la nación mexicana; en este contexto las haciendas buscaron recuperarse y algunos propietarios se relacionaron con el poder político, como lo fue el caso de Jalpa, cuyo dueño recibió el apoyo y el padrinazgo del presidente Porfirio Díaz. Sin embargo, las haciendas del Bajío no lograron los altos niveles productivos del siglo anterior. Ante esta situación, durante el siglo $\mathrm{XX}$, las haciendas se fueron subdividiendo por procesos de compra-venta y su paulatina desaparición se fue dando posteriormente, desde 1910, cuando se produjo la revolución mexicana que motivo la implementación de la reforma agraria.

\section{La hacienda Jalpa de Cánovas}

A nivel interno, la historia de Jalpa empieza en 1544. En este año las tierras fueron mercedadas al encomendero de Huango, Juan Villaseñor (Goyas y Navarro, 2013: 291). En 1616 en dichas tierras vivían aún grupos de indígenas chichimecas quienes fueron expulsados. Desde ese momento hasta 1634 Jalpa se consolidó como una gran propiedad (Martínez, 1997: 22). Posteriormente, la propiedad fue adquirida por Diego Ortiz de Saavedra, alguacil mayor de la villa de Santa María de los Lagos, sin embargo, debido a sus deudas en 1650 la hacienda fue rematada y la compró Andrés Sánchez de Aparicio. En 1679-1680, el hijo de Sánchez lo vendió al empresario minero de Guanajuato Nicolás de Busto y Jerez. Después, en 1698-1699, fue vendido a otro minero, el propietario de las minas San Juan de Rayas, Juan Diez de Bracamonte. (Brading, 1973: 213; Rionda, 1982: 22). Sin embargo, el empresario entró en crisis y tuvo que vender la propiedad.

En 1708 la hacienda fue adquirida por el comerciante español Jerónimo Monterde y Antillón. Durante todo el siglo XVIII y parte del siglo XIX los descendientes de Monterde asumieron la propiedad a través de herencias familiares. Jerónimo de Monterde fue vecino de la ciudad de México y dueño de casas y negocios en Veracruz. Inicialmente, dedicó la hacienda a la producción de ganado mayor con la crianza de animales de carga, aunque también le dio importancia a la crianza de ganado menor como la de borregos (Martínez, 1997: 23). Al fallecer en 1712, su hermano Luis Monterde asumió la propiedad y en 1720 adquirió más tierras. Así la hacienda alcanzó una extensión de 37 sitios y 67 y medio caballerías (Brading, 1973: 217). Un sitio para ganado mayor medía, en términos actuales, 1755.61 hectáreas (Orozco, 1895: 742-743); la extensión de una caballería era de 42.79 hectáreas (Brading, 1978: 66). En los sitios principalmente se desarrolló la actividad ganadera y esta se ubicaba en los Altos de Jalisco, mientras que las caballerías eran extensiones de tierras cultivables, las mismas que se encontraban en el Bajío.

Hacia 1739, José Luis Monterde, hijo de Luis Monterde, se hizo cargo de la hacienda. Sin embargo, las sequías de 1739 y 1746-47, provocó la muerte de miles de cabezas de ganado y afecto al campo agrícola. Ante esta situación, en 1749, proyectó construir presas para almacenar el agua. Una de ellas, la presa vieja se construyó a partir de 1750. Sin embargo, su terminación se dio en 1764 cuando era propietario Rafael Monterde y Antillón (Brading, 1973: 217). Con las construcciones hidráulicas se crearon amplios perímetros de riego ${ }^{2}$ revalorizaron la propiedad con más tierras de cultivo.

Para los Monterde la producción agrícola y ganadera no estuvo desligado de la política. En 1771, el capitán Rafael Monterde estuvo a cargo de la administración de justicia y precedía las ceremonias de elección de gobernadores en el distrito de León (Goyas y Navarro, 2013: 294). Este año, Rafael fue comisionado por el visitador general de la Nueva España, José de Gálvez, para que elabore una nueva lista de tributarios y logró recaudar 19000 pesos (Brading, 1975: 319). Esta relación política, la culminación de 
Teoría y Práctica de la Arqueología Histórica Latinoamericana | Año VIII. Vol. 8 | 2019

ISSN en línea: 2591-2801 | ISSN versión impresa: 2250-866X

la construcción de la presa y la pertenencia a una clase encumbrada social y económicamente le permitió a Rafael Monterde y su esposa María Micaela Monterde, a recibir en 1775, el título de Condes de la Presa de Jalpa y Viscondes de Valda San Pedro (Brading, 1973: 217).

En cuanto a la hacienda misma, por su extensión territorial, no fue trabajado directamente por los dueños, sino que la subdividieron internamente y la arrendaban. Sin embargo, esta situación perjudicó una parte de la propiedad. Los arrendatarios, ubicados en tierras orientados a la ganadería, en lo que hoy se conoce los Altos de Jalisco, se unieron en 1762 y decidieron fundar el pueblo de Santa María de Guadalupe de los Arandas. Posteriormente, en 1790 la villa de Arandas paso a depender de la vicaría de la parroquia de Ayo el Chico y en 1803 se convirtió en cabecera parroquial (Martínez, 1997: 26).

Como ya lo señalamos, la hacienda de Jalpa abarcaba parte del territorio de los Altos de Jalisco, la misma que dependía político y administrativamente del reino de la Nueva Galicia y la región del Bajío dependía de la Nueva España. En lo relativo al pago de alcabalas, diezmos y otros impuestos, los propietarios debían pagar tanto en la villa de Lagos, Nueva Galicia, como en la de León, Nueva España. Sin embargo, para las autoridades de la villa de León esto ocasionaba una evasión de impuestos. Por eso, en 1788 los de León solicitaron que se cotice totalmente en esta villa debido a que el casco principal de la hacienda estaba en la jurisdicción de León. Finalmente, la audiencia de México determinó que se continuará tal como estaba acostumbrado. En realidad, la producción de Jalpa y su comercio se relacionó con los centros urbanos y las minas que se encontraban en el reino de la Nueva España. Incluso la producción ganadera de los Altos de Jalisco salía en dirección a la Nueva España y con ello evadía impuestos en la Intendencia de Guadalajara (Goyas y Navarro, 2013: 295).

A nivel regional, podemos apreciar que el éxito productivo de las haciendas en el siglo XVIII se debió a cuatro factores: contaron con tierra fértil, aprovecharon las aguas de temporal, tuvieron mano de obra indígena asalariada y arrendatarios, y construyeron sistemas hidráulicos eficientes que les permitió almacenar, controlar y usar el agua para el riego.

Todos estos factores permitieron una alta producción de las haciendas en el Bajío y por ello fue reconocido como la "Mesopotamia” mexicana (Morin, 1979: 21), “ejemplo de fecundidad bien admirable”, "planicie rica que produce frutos de Europa y los trópicos” (González, 1980: 101), o como el “granero de la Nueva España” (Olivares, 1985: 8; Rionda, 1985: 10) y, el "granero de México” (Sánchez, 2002: 20; Wolf, 1972: 69).

En el contexto del reino de la Nueva España, fue un período de auge económico porque las diversas actividades económicas se articularon y se desarrollaron en paralelo. La agricultura, la transformación cerealera en harina en los molinos hidráulicos, la ganadería, la minería, el comercio y las manufacturas convirtieron al Bajío y sus regiones adyacentes en el “centro económico de la Nueva España” (Brading, 1975: 301).

En la escala mundial, la actividad minera, que se desarrolló adyacente al Bajío, abasteció con la plata en monedas que requería España para su comercio. La plata novohispana llegó a todos los continentes, incluso llegaba directamente a China, ya que el valor que alcanzaba el metal era mayor que en la propia Europa. El sistema-mundo considera a Europa como su núcleo, y a través de los viajes de conquista los europeos convirtieron a distintas naciones en lugares dependientes semiperiféricos y periféricos (Wallerstein, 1979: 53-54).

Para nuestro caso de estudio, España en el siglo XVIII, fue considerado como el centro del sistemamundo y la Nueva España era un espacio periférico. Sin embargo, en este siglo el virreinato novohispano, a través del Bajío, que se convirtió en el núcleo económico del sistema-mundo (Tutino, 2016), y la España misma sólo fue el núcleo político que usaba las monedas mexicanas para su comercio con el mundo 
Teoría y Práctica de la Arqueología Histórica Latinoamericana | Año VIII. Vol. 8 | 2019

ISSN en línea: 2591-2801 | ISSN versión impresa: 2250-866X

de entonces. Así vemos que las actividades económicas agro-ganadera, de transformación y de comercio del Bajío convivieron con la actividad minera y esta última sostuvo y consolidó al sistema-mundo.

Posteriormente, en 1810 la región abajeña se convirtió en el epicentro del movimiento insurgente que luchó por la independencia. Esta situación paralizó las actividades económicas, entre ellas la minería de plata. Las haciendas y las demás unidades productivas fueron ocupadas por las fuerzas insurrectas y realistas. En este período el propietario de Jalpa era Pedro de Cevallos, en 1821 se unió a la causa patriótica y juró la independencia del reino (González, 2006: 47).

Superada la coyuntura independentista surgió la nueva nación mexicana. Las haciendas empezaron a retomar sus actividades, pero la crisis económica hacía difícil la inversión en las actividades agrícolas y ganaderas. En 1827, la actividad ganadera en Jalpa se vio disminuida, por ello, se decidió vender parte de los terrenos que se encontraban en Los Altos. Los compradores fueron rancheros que se habían establecido inicialmente como arrendatarios (Brading, 1973: 218; Martínez, 1997: 28). Esta situación casi se generalizo con las demás haciendas y provocó el decaimiento de las propiedades (Martínez, 1997: 27).

Hacia mediados del siglo XIX, la propiedad de la hacienda paso a manos de la hija y heredera de Pedro Cevallos, Ignacia Cevallos Monterde y Antillón. En 1864, Ignacia se casó con Manuel Cánovas, pero al no tener descendencia y al fallecer en 1865, la propiedad paso a manos del propio Manuel Cánovas. Posteriormente, Manuel se volvió a casar, esta vez con Octaviana Portillo, con quien tuvieron una hija, Guadalupe Cánovas.

En el contexto de la organización territorial de la nación mexicana en 1867, el gobernador del Estado de Guanajuato, León Guzmán creó las municipalidades de la Purísima y de San Francisco dependientes del partido de León. La hacienda Jalpa paso a depender de la jurisdicción de Ciudad Manuel Doblado, pero a partir del 29 de mayo de 1872, el Congreso del Estado determinó su anexión a la Municipalidad de Purísima del Rincón (Zamora, 2010: 61).

En 1882, Guadalupe Cánovas heredó la hacienda y al casarse con Oscar Braniff en 1900, la hacienda tuvo un aceptable repunte productivo (Collado, 1987: 88). En esta nueva etapa, la hacienda se orientó a la siembra de trigo, cubriendo el $41 \%$ de su territorio con esta actividad, aunque una parte de ella estaba sembrada por arrendatarios o aparceros. Para la producción agrícola se contaba con 1800 peones cada año. Con Braniff, se diversificó la producción agrícola y se introdujo la siembra de árboles de nogales; además, se construyó una segunda gran presa. Por otro lado, la familia Braniff, estaban vinculados a diversos negocios, tenían inversiones en minas, inmuebles, la industria textil, era accionista del Banco de Londres y México; además, fue director de la empresa ferrocarriles de México.

El patriarca de los Braniff, Thomas, fue quien inició la diversificación de inversiones. Así se hizo de un nombre y perteneció a la burguesía mexicana en la etapa porfiriana. Sus cinco hijos, entre ellos Oscar, a través del padre tuvieron relaciones con el gobierno de Porfirio Díaz. Esto le favoreció para que se construyera el ferrocarril que pasaba cerca de la hacienda de Jalpa.

La hacienda, aparte de sembrar trigo y nogales, también sembraba alfalfa, maíz y trébol. Pero, en las tierras, que aún tenía en Los Altos de Jalisco, se orientaron a la crianza de vacunos. Contaban con ocho a diez mil cabezas de reses. Incluso, criaron toros de lidia, especialmente para las fiestas taurinas (Collado, 1987: 88-91).

Al final del gobierno de Porfirio Díaz, Oscar Braniff y otros miembros de la burguesía fueron comisionados para realizar un estudio relacionado con el crédito agrícola. Braniff propuso realizar cambios para fomentar la actividad agrícola en el país, ya que era consciente de los problemas agrarios en México (Collado, 1987: 94). En 1910, planteó que el estado debía promover la agricultura otorgando premios a los que la produjeran más. No estaba de acuerdo con entregar créditos por que los campesinos no tenían 
poder adquisitivo y la baja productividad en México produciría una pérdida de la inversión. Por otra parte, planteó que las grandes propiedades debían fraccionarse, porque así se obtendría una mayor producción por unidad de tierra y esto crearía una clase media. Aunque, sugería que el fraccionamiento debía ser voluntario. También, propuso que se titularan las tierras.

En cuanto al uso de las aguas, sugirió que estas no debían ser repartidas junto con las tierras, sino que debían respetarse los derechos de aquellos que la habían gozado por más de diez años. Sobre el manejo de la racionalización de las aguas se pensó en crear empresas suministradoras de agua, pero bajo la vigilancia del gobierno (Collado, 1987: 94,95). Con Braniff, siendo del grupo de la burguesía mexicana, se levantó una voz autorizada relacionada a la reforma agrícola. Su experiencia en el manejo de la hacienda Jalpa le hizo ver las dificultades que atravesaba la actividad agrícola, pero también, planteó, algunos puntos, como los derechos de agua, que favorecía a sus intereses.

Con la lucha durante la revolución mexicana, muchas propiedades fueron afectadas. Jalpa no fue la excepción, en 1915 fue confiscada por el gobierno constitucionalista de Carranza, y ante ello, Oscar Braniff pidió que le fuera reintegrado y el gobierno las devolvió (Collado, 1987: 152). Con el triunfo de la revolución mexicana, la propiedad latifundista llego a su fin. La propiedad fue dividida y se vendió en su totalidad, salvo el casco de la casa hacienda que quedo en manos de la familia Braniff (Brading, 1973: 217).

\section{EI sistema hidráulico de la hacienda}

Como ya se ha señalado, en el período novohispano y parte de la etapa republicana el territorio de la hacienda Jalpa de Cánovas abarcaba tierras de lo que hoy se reconoce como la región de los Altos de Jalisco y El Bajío, es decir lo que fue el reino de la Nueva Galicia y la Nueva España respectivamente. Hoy corresponden a los Estados de Jalisco y Guanajuato. El territorio de la hacienda, vista de manera transversal de Oeste-Este, comprende en un 75\% a la región de los Altos de Jalisco y el 25\% al Bajío (Rodríguez, 1984: 63).

La arqueología histórica nos ha permitido identificar y reconstruir el sistema hidráulico que se construyó en Jalpa, los recorridos de campo y la revisión documental han sido importantes. A la vez, el reconocimiento del territorio y la evidencia de la cultura material nos ha permitido apreciar las transformaciones en el medio geográfico y la adaptación social al entorno.

El éxito agrícola de la hacienda Jalpa se inició cuando se construyó una primera presa, que se ubicó en el límite de la región de los Altos de Jalisco y el Bajío. La presa permitió almacenar el agua de las lluvias de temporal y de las escorrentías que bajaban por las distintas cañadas de los Altos de Jalisco. El control del agua ayudó a irrigar espacios agrícolas en el Bajío, a la vez, el líquido se convirtió en un recurso económico porque se vendía a los hacendados que se ubicaban al sur de Jalpa. Por otro lado, en el territorio abajeño, por la hacienda cruzaba el río Turbio en dirección Norte-Sur. Ambas fuentes de agua permitieron ampliar las zonas agrícolas y en mantener una producción constante durante el año. Con las lluvias estacionales se producía maíz y después durante el invierno, con el riego, se producía trigo. 


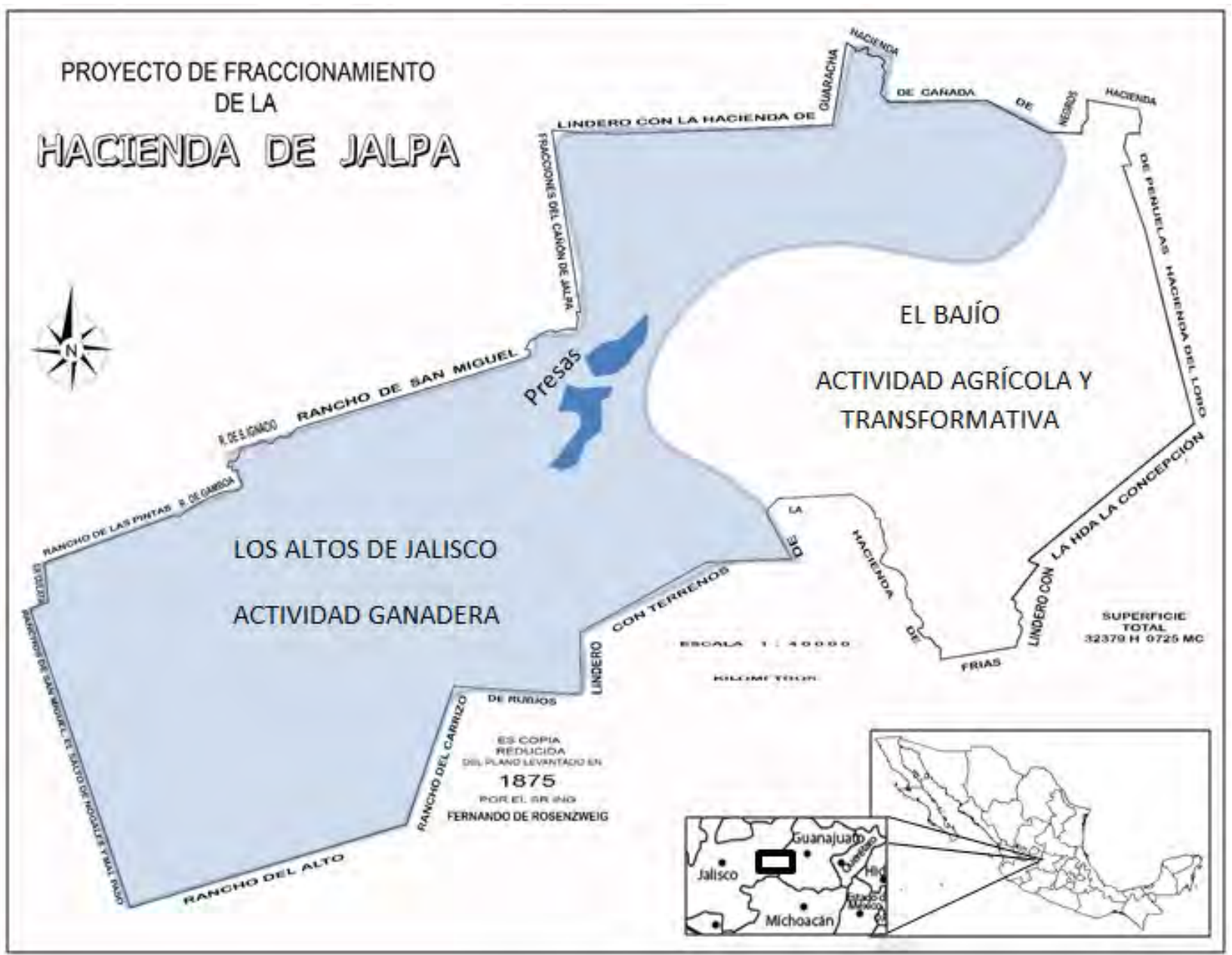

Figura 1. Plano de la hacienda Jalpa de Cánovas, basado en el plano del Ing. Civil Fernando Rosenzweig, 1875. El plano se encuentra en el casco de la ex hacienda de Jalpa, Guanajuato.

En 1749, el propietario de Jalpa, José Luis Monterde, decidió construir cuatro presas en los arroyos que bajaban de los Altos de Jalisco. Inicialmente, la intención fue para disponer de abrevaderos para el ganado y para fomentar el sembrío de trigo. En 1750 empezó la construcción de una de las mayores presas de la hacienda, la “presa vieja o de Santa Eduviges”. Para tal propósito se hizo un préstamo de 15000 pesos del Convento de la Concepción en México. Sin embargo, solo tenemos referencias de la construcción de una presa, en cuanto a las otras tres no sabemos si se construyeron. Aunque, por la envergadura de la obra, al parecer la inversión realizada solo alcanzó para la “presa vieja”. En 1764 la construcción aún no se había culminado y el nuevo propietario, Rafael Monterde y Antillón, tuvo la necesidad de solicitar otro préstamo, de 16000 pesos, con lo cual se pudo terminar la obra (Brading, 1973: 217). La presa es un paramento de talud reforzada con contrafuertes, fabricado en mampostería; mide unos 265 metros de largo y en su punto más alto tiene una altura de 26 metros. El vaso receptor tuvo una capacidad de 7,827,000 $\mathrm{m}^{5}$. Se ubicó sobre el brazo norte del arroyo de Jalpa, y a través de canales y bordos se direccionó las aguas para irrigar unas 20 mil hectáreas de la hacienda (Martínez, 1997: 23).

El agua de esta presa desciende bruscamente hacia el valle por una cañada, y se deposita en otra presa situada a un kilómetro y medio río abajo, y a partir de la cual se derivaba finalmente por los dos 
flancos del curso del río, de hecho, la presa se conoce como "La Repartidora" y su embalse era de 1,500,000 metros cúbicos ${ }^{3}$ El agua que se derivaba de esta presa por la rivera izquierda, se hacía llegar hasta el valle por canales de mampostería y ladrillo, mientras que por la ladera derecha se conducía el agua, por un acueducto soportado por arcos de mampostería, hacia el área que circunda el casco de la hacienda. En la desembocadura de la presa, a unos 300 metros, en la margen izquierda del arroyo de Jalpa se construyó un molino, con dos piedras de moler, movidos por fuerza hidráulica.

En 1865 Ignacia Cevallos Monterde y Antillón, la última heredera de los Monterde, casada con Manuel Cánovas, falleció sin dejar descendencia. El viudo Cánovas se hizo de la hacienda y volvió a casarse, en su segundo matrimonio tuvo una hija al que llamó Guadalupe Cánovas. En 1875, Manuel mandó elaborar un plano de la hacienda donde se aprecia la mayoría de la infraestructura hidráulica. En este documento se puede observar, aparte de la presa, todo un sistema de cortinas de mampostería, de baja altura, y entarquinamientos ubicados en la zona del Bajío. Los entarquinamientos, conocidos también como cajas de agua o bordos permitían captar el agua para humedecer el terreno y después de derivar el agua, bien a otras cajas o al río Turbio, se procedía a sembrar. El plano fue elaborado por el ingeniero Fernando de Rosenzweig, el mismo que trazó el Paseo de la Reforma en la ciudad de México.

En el siglo XX, durante el porfiriato en Jalpa se construyeron otros sistemas hidráulicos complementarios. Sobre el curso del río Turbio, en su paso por el territorio de la hacienda, se construyeron dos cortinas de mampostería que dieron lugar a presas muy extensas a manera de terraplén. Una primera cortina se construyó justo en el límite norte del territorio de la hacienda, es decir en el punto más alto donde se podía aprovechar el trayecto del río. Su funcionamiento se dio por medio de una presa móvil que dicha obra derivaba las aguas del río por la margen izquierda; la represa estaba compuesta por ocho compuertas, de dos metros de alto, que con todo y un muro de contención suman una longitud de 40 metros aproximadamente, la construcción se completaba con un terraplén o bordo de tierra de aproximadamente 1,700 m. de largo, que delimitaba al vaso por su parte frontal.

Dos kilómetros río abajo, se construyó otra cortina consistente en un gran paramento en talud fabricado en mampostería, que en su punto más alto mide casi cuatro metros y de longitud conserva casi los $500 \mathrm{~m}$. Aunque la presa retenía agua del río Turbio ésta se desarrolló básicamente sobre la margen derecha del cauce, pues al parecer también tomaba agua de una pequeña corriente estacional que derivaba aguas sobre la margen derecha del Turbio.

Esta clase de presas, sobre el río, son muy extensas, pero poco profundas, esto nos refiere a un tipo de técnica de riego para el cultivo basada en el entarquinamiento (Sánchez, 2006). Este tipo de riego implicó la inundación controlada en períodos de lluvias, con lo cual se facilitó la humidificación de la tierra, la fertilización con la incorporación anual del tarquín o materia orgánica arrasada por la corriente, también ayudó en el combate de las plagas animales y vegetales, a la vez que facilitó algunas labores de cultivo. Así las presas antes mencionadas no sólo derivaban aguas del Turbio, sino que funcionaban también como áreas de cultivo en época de estiaje. Ubicadas en el punto más alto del curso del río y por ende en la parte más alta del valle, respecto a los límites de la propiedad, el agua que se derivaba alimentaba las tierras de la margen izquierda del río, conformando un perímetro de riego que en su parte más extensa cubría una distancia de casi cinco kilómetros por cuatro de ancho, esto es que se regaba parte del valle que corresponde al extremo nororiente de la propiedad.

Siguiendo hacia el sur por el valle, por el lado izquierdo con respecto al curso del río, se formaba una ciénaga y un pequeño riachuelo de los cuales también se aprovechaban sus aguas para riego, para esto se construyó un terraplén o bordo que contenía las aguas de estas fuentes antes de que desaguaran sobre el Turbio; dicho bordo tenía una longitud total de más de dos kilómetros, pues en parte retenía 
Teoría y Práctica de la Arqueología Histórica Latinoamericana | Año VIII. Vol. 8 | 2019

ISSN en línea: 2591-2801 | ISSN versión impresa: 2250-866X

aguas hacia el sur y otra bordeaba la rivera del propio río Turbio, formando de esta manera una gran superficie de riego por entarquinamiento, lo cual definía otro perímetro de riego, en este caso en el límite suroriental de la propiedad.

El ingeniero Fernando de Rosenzweig también elaboró un proyecto para la construcción de una nueva presa sobre el brazo sur del Arroyo de Jalpa, proyecto que finalmente se ideó y ejecutó en parte por el arquitecto y relojero Luis Long (González, 2006). Esta segunda gran presa se construyó a partir de 1900, al parecer conjuntamente con un molino de harina. Los últimos dueños, Guadalupe Cánovas y su esposo Oscar Braniff fueron los últimos propietarios de la hacienda hasta 1931, año en que se procedió a su fraccionamiento y venta.

La llamada “presa nueva” tuvo una capacidad de almacenamiento de $60000 \mathrm{~m}^{3}$. Las dimensiones de la cortina vertical midieron $550 \mathrm{~m}$. de largo y $92 \mathrm{~m}$ de altura. Al disponer de dos presas, Jalpa contaba con suficiente agua para sus campañas agrícolas e incluso vendía el agua excedente a diversas haciendas vecinas. Al mismo tiempo, Braniff construyó un molino de trigo, movido por fuerza hidráulica, con lo cual le dio valor agregado al trigo que justamente se sembraba en los campos de riego. Desde inicios del siglo XX, Jalpa fue modernizada con la tecnología más avanzada de su época, contaba con trilladoras a motor de gasolina, planta eléctrica y gran variedad de herramientas.

La "presa nueva”, bautizada como "Santa Ifigenia" se construyó casi a la misma altura de la "presa vieja” o "Santa Eduviges” y cumplía las mismas funciones básicas que las referidas para la primera; así, el agua de dicha presa tan sólo se hizo conducir a la presa Repartidora, por lo que de esta forma el sistema arroyo abajo siguió funcionando de la misma manera como lo hacía con una sola presa. El sistema arroyo abajo se repartía por las dos laderas del río, resultando ser el más extenso el que se relacionaba con la derivación de las aguas del arroyo por su margen izquierda, con estas aguas se regaban principalmente las tierras para cultivo ubicadas hacia la margen derecha del Río Turbio, y más específicamente la zona noroeste del valle con respecto a los límites del territorio de la hacienda, aunque también, según se puede apreciar por los restos de un acueducto construido básicamente de ladrillo, podía aportar agua al perímetro dominado por las presas ubicadas sobre el Turbio.

Vale apuntar que aunque se trata de un riego por gravedad, sobre todo en la margen derecha del Turbio, éste tenía la particularidad que en su mayoría el agua se distribuía por medio de áreas de entarquinamiento, lo que implicaba la construcción de terraplenes o bordos que retenían el agua e inundaban estacionalmente el terreno de cultivo, esto es como en las presas mencionada para el Turbio, pero en estos casos siguiendo el curso provocado por la mano del hombre y aprovechando corrientes naturales de menor aforo, por ejemplo, siguiendo la pendiente del terreno, es decir de norte a sur, la primera zona de entarquinamiento, aparte de estar relacionada con el canal que baja de la presa, está claramente diseñada para recibir también aguas de un riachuelo que baja justamente por su lado norte, esto es, la compuerta de entrada se construyó sobre el cauce del riachuelo; así, la distribución del agua se realizaba por medio de compuertas colocadas estratégicamente sobre los bordos, pasando el agua de un área de entarquinamiento o caja de agua a otra terrenos abajo.

El perímetro de riego formado desde la Presa repartidora, cubría el valle entre el río Turbio y el Arroyo Jalpa en su parte norte hasta la derivación de otro perímetro que partía de otra presa construida sobre el curso del mismo Arroyo. Ya en el valle, a $1.5 \mathrm{Km}$. antes de la intersección de los dos brazos del Arroyo Jalpa, se construyó una presa derivadora, fabricada en mampostería y tierra a manera de terraplén, compuesta por 16 compuertas, de una altura máxima de dos metros y que con sus diferentes secciones cubría una longitud de más de 300 metros. Dicha presa principalmente regaba los terrenos que se encuentran entre los dos corrientes, la del Turbio y el propio Jalpa, pero en esta ocasión sobre la parte 
sur hasta los límites del territorio de la hacienda, y de la misma forma que lo sucedido en el perímetro de riego dominado por las presas localizadas arroyo arriba, en esta sección el sistema de cultivo también consistía básicamente en el entarquinamiento de grandes extensiones de terreno; por ejemplo las cajas de agua, o también llamados vallado, relacionados con este perímetro de riego mantenían grandes “espejos” de agua cuyas capacidades iban desde el 1,480,000 metros cúbicos, hasta los 3,843,000 metros cúbicos. Así en total, estos dos perímetros de riego que cubrían casi en su totalidad el valle entre el Jalpa y el Turbio, tenía en su parte más ancha casi los cuatro kilómetros, y de largo, es decir de norte a sur, más de seis kilómetros.

Para terminar de referir el uso de las aguas derivadas desde el arroyo Jalpa, es necesario mencionar que por la margen derecha, el sistema regaba (y sigue regando) las huertas aledañas al casco de la hacienda y también, mediante el acueducto soportado por la arcada, el agua se usaba para hacer mover la maquinaria de un molino para harina. Desde la presa repartidora hasta el molino, el acueducto cubrió una distancia total de más de ochocientos metros, de los cuales el acueducto soportado por la arquería cubrió un poco más de cuatrocientos metros.

Por su parte, pero también sobre los límites del valle del Turbio y las estribaciones de los cerros que lo delimitan por su lado poniente, a unos tres kilómetros hacia el sur con respecto al casco de la hacienda, se construyó una presa almacenadora que definía un perímetro de riego más pequeño que los antes referidos, entre la margen derecha del Arroyo Jalpa y las estribaciones de la serranía. Dicha presa se construyó sobre un arroyo que confluía sobre la margen derecha del Jalpa, esto antes de rodear una loma que interrumpe el paso directo desde el oeste hacia el este, formando un pequeño valle de poco más de dos kilómetros de largo por apenas 300 metros de ancho, denominado precisamente la Cintilla, área que finalmente se aprovechó para riego con el agua almacenada por la presa. La presa se construyó en mampostería y mantiene una altura de más de cinco metros por una longitud que sobrepasa los 100 metros.

Si en términos técnicos la racionalidad y efectividad del sistema significaba el control de grandes perímetros de riego, con lo cual finalmente se transformó el paisaje adaptándolo socialmente. La envergadura de las obras, por otro lado, nos remite a comprender la inversión que se realizó, tanto en la cantidad de material empleado, recursos económicos y principalmente de la disposición de una organización social para el trabajo.

Ya en el valle y recapitulando sobre lo ya expuesto hasta el momento, la producción agrícola de la hacienda se basaba en la ocupación de prácticamente todo el valle comprendido por la propiedad. Grosso modo, dicha ocupación se definía por cinco perímetros de riego, los que tomaban agua principalmente del Río Turbio y del Arroyo Jalpa, uno de los principales afluentes del Turbio, pero también de afluentes menores y cuerpos de agua como las ciénagas.

Así pues, se trata de un aprovechamiento total de las aguas superficiales, el cual se basaba principalmente en el almacenamiento y entarquinamiento como medio de control de las aguas estacionales características del régimen hídrico de la región. Se trató de un sistema altamente eficiente, pero como todo sistema basado en la distribución del agua por gravedad, sobre todo uno tan complejo como el del entarquinamiento y que en cierta medida depende de aguas estacionales, la desarticulación de un elemento del sistema altera el funcionamiento de todo el perímetro de riego; en otras palabras, la extensión del perímetro de riego es constitutiva de la propia técnica de riego. 


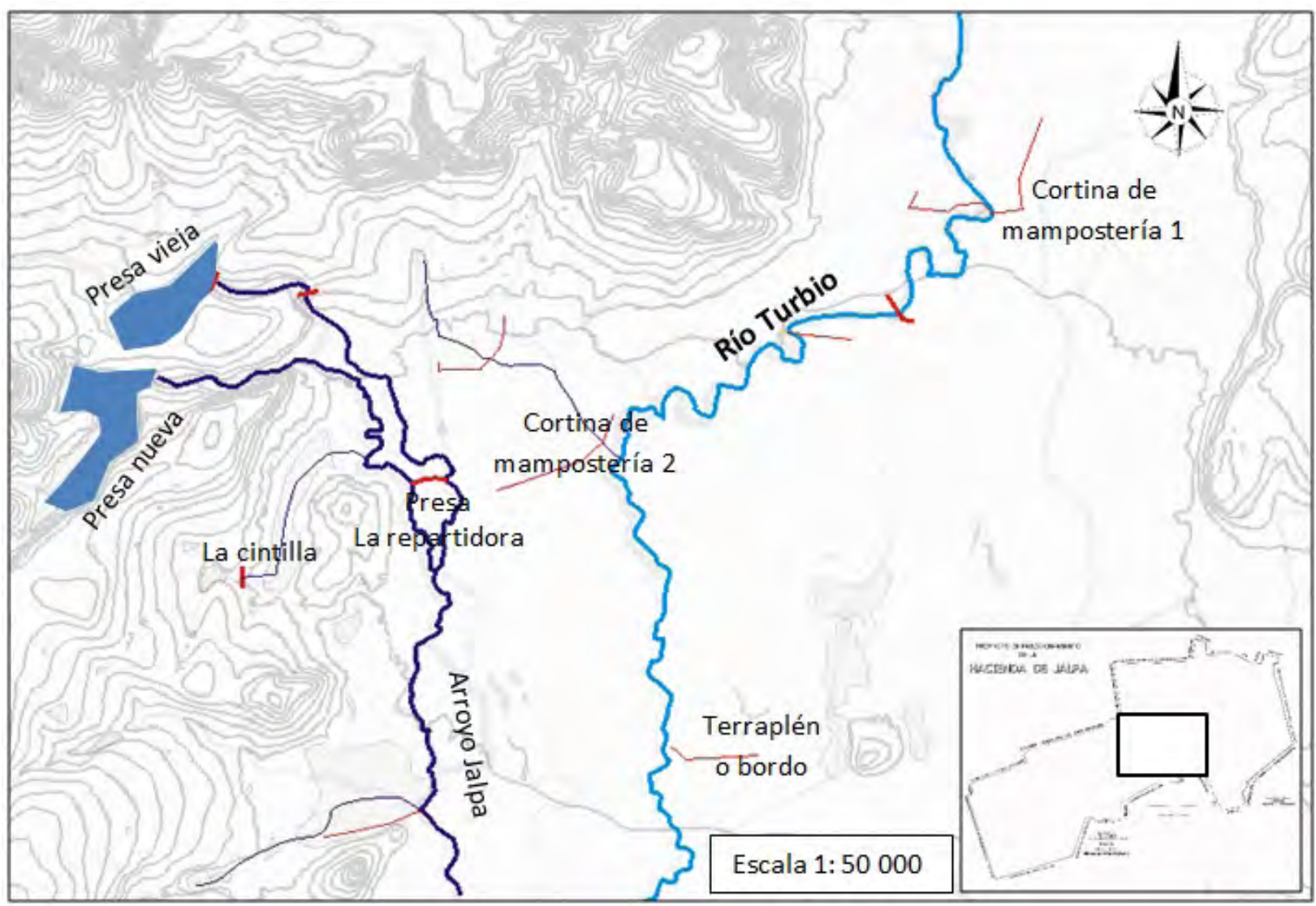

Figura 2. Tipos de infraestructura hidráulica: Presa vieja (1750), Presa nueva (1900), Cortinas de mamposterías y otros (siglos XVIII-XIX).

Por su parte, dicho sistema implicó la construcción de grandes obras las cuales han dejado su impronta hasta nuestros días. Pero esta infraestructura hidráulica no sólo configuró el parcelario entre ríos, sino también la ocupación social e infraestructura relacionada con la producción agrícola; por ejemplo, cuatro de los perímetros de riego se asocian con sendos asentamientos humanos. Relacionado tanto con el punto de origen del perímetro principal como con la mejor zona en donde se pudiera aprovechar la fuerza del agua, es decir entre el contacto de la sierra con el valle, se desarrolló el casco de la hacienda, donde se estableció el molino, representante de la culminación del proceso agrícola antes de la distribución del producto.

Todo este sistema funcionó con efectividad mientras la hacienda conformaba una sola gran unidad. Sin embargo, como se ha comentado la revolución mexicana marco el inicio para la conversión de la propiedad. Posteriormente, hacia 1931, Jalpa se fraccionó y de ser de un solo propietario paso a convertirse en propiedad de muchas personas. Principalmente, los arrendatarios de las tierras de la hacienda compraron las fracciones. Pero, a su vez esto generó una serie de problemas entre ellos, principalmente referidos al control, distribución y uso del agua. Para ello, el propio Estado mexicano, a través del Ministerio de Agricultura se ocupó de las concesiones del agua y de solucionar los casos sociales. Pero esta es otra historia que no nos alcanza a profundizar en este trabajo. 


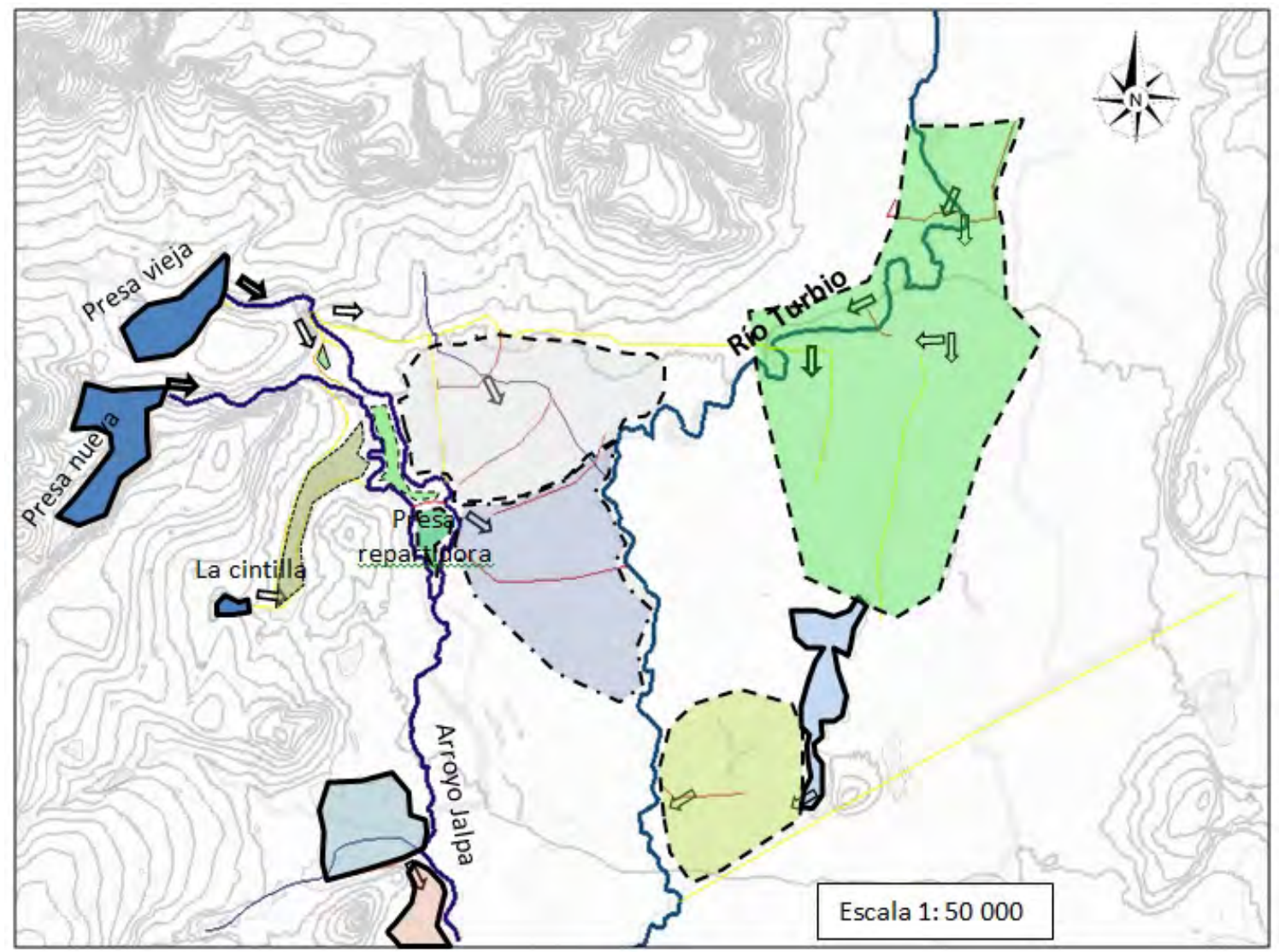

Figura 3. Esquema de los perímetros de riego.

\section{El Bajío y el sistema-mundo}

Los sistemas hidráulicos de la hacienda de Jalpa permitieron aprovechar la ampliación territorial irrigable lo que determino su constante producción anual. En el siglo XVIII la actividad minera requirió del abastecimiento permanente de alimentos e insumos, por lo cual todas las actividades productivas, transformativas y comerciales se desarrollaron paralelamente. El Bajío fue la región de confluencias económicas y esto favoreció al virreinato novohispano, que finalmente, gracias a la plata se convirtió en el núcleo económico del sistema-mundo. Más aún, siendo un lugar periférico para España, fue el centro que mantuvo a la Corona y contribuyó a la consolidación del sistema capitalista (Tutino, 2016).

Sin embargo, la entrada al siglo XIX, significó de grandes cambios para el Bajío y las regiones adyacentes. Primero fue la lucha por la independencia que, teniendo como escenario a la región del Bajío hizo decaer y en algunos casos paralizó las actividades agropecuarias y, por otro lado, en el contexto internacional la plata mexicana menguó tanto en su producción como en su circulación. Posteriormente, con el establecimiento de la nueva nación mexicana los centros productivos trataron de reactivarse, pero no lograron tener la alta producción del siglo XVIII. El contexto político y económico dependiente de las nuevas potencias que se configuraban internacionalmente hizo de México, esta vez en un lugar periférico. Finalmente, la lucha por la justicia social que planteó la revolución mexicana desde 1910, obligó a una nueva configuración territorial de la propiedad rural. Con la reforma agraria las haciendas y los latifundios dejaron de ser un pilar productivo y económico en la república mexicana. 


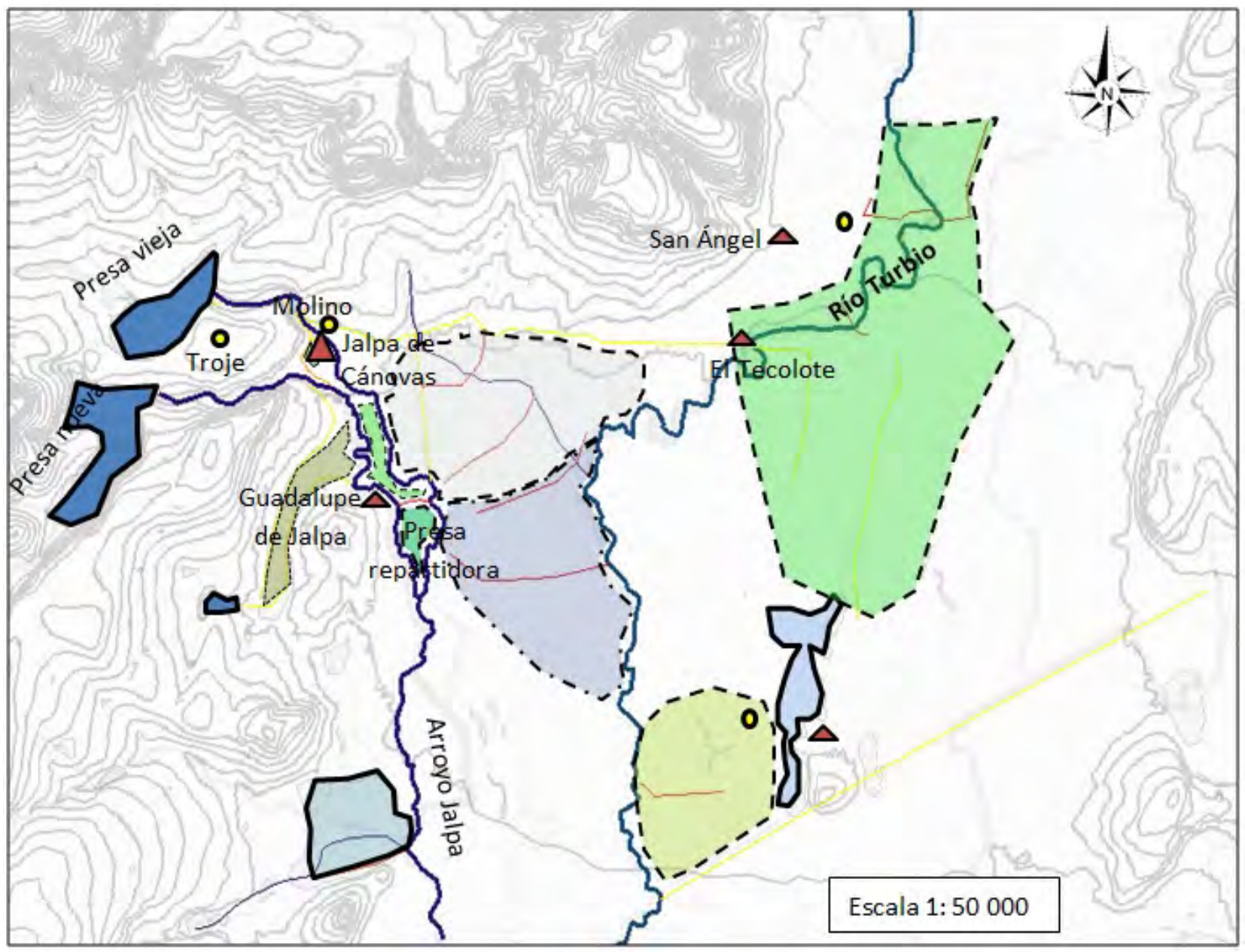

Figura 4. Centros de población y perímetros de riego de la hacienda Jalpa de Cánovas.

\section{Conclusiones}

Como vemos todo este sistema tecnológico referido al manejo y control del agua, desde 1750, permitió a la hacienda Jalpa, en convertirse en una de las instituciones económicas productivas de la región. Por tener un territorio diferenciado por pisos altitudinales tuvo actividades económicas complementarias. En el Bajío se fomentó la agricultura y en los Altos de Jalisco la ganadería. Pero este desarrollo también tuvo repercusiones en el ámbito ecológico, el medio natural se transformó y permitió la adaptación social al entorno. La población abajeña dedicada a la agricultura, a la manufactura y a la transformación de cereales en harina, además del comercio, fue más citadino, mientras que la población de los Altos de Jalisco dedicados a arrendar tierras para su subsistencia, se orientó a la ganadería; al independizarse los espacios arrendados dieron origen a los ranchos y con ello se constituyó a través del tiempo en la cultura ranchera que tuvo entre una de sus manifestaciones la forma de montar a caballo, que después se convirtió en la imagen del mexicano del ámbito rural de Jalisco. 
Bajo estas características, ya sean agrícolas, ganaderas o mixtas, las haciendas de la región también lograron desarrollarse y sumadas a otras actividades económicas paralelas, convirtieron al Bajío en el centro económico de la Nueva España. Más aún, la plata que producía la minería en la región argentífera adyacente, en el siglo XVIII convirtió al Bajío en el núcleo económico del sistema-mundo.

Pero, todos estos alcances se vieron disminuidos durante la etapa independentista y con el establecimiento de la nueva nación mexicana, en el siglo XIX y XX, los hacendados apostaron por invertir en una mayor producción agrícola, en la ampliación de los sistemas hidráulicos y la modernización industrial; sin embargo, no se alcanzó los altos niveles productivos del siglo anterior.

En este último proceso, para el caso del dueño de Jalpa, al pertenecer a la clase social empresarial se relacionó políticamente con el gobierno de turno. Oscar Braniff tuvo una cercanía con el presidente Porfirio Díaz, lo cual le favoreció con la construcción del ferrocarril que pasaba cerca de la hacienda, además pudo contar con energía eléctrica. Pero aún así, como ya lo hemos referido no se alcanzó los picos productivos del siglo XVIII.

En el período novohispano el reino de la Nueva España fue una prolongación del reino español en el sentido legal y oficial; la corona española no lo reconocía como colonia, por ello nombraba como autoridad a un doble del rey (Altuve, 1996; Alvarado, 2017; Levene, 1973). España en este período sólo fue el centro político y militar. En el siglo XIX-XX, la nueva nación mexicana se insertó al sistema económico industrial internacional, la minería dejó de ser un pilar importante en la economía por el agotamiento de sus reservas y las otras actividades económicas decayeron y debido a ello tuvo que someterse a las nuevas reglas económicas del capitalismo que impusieron de las nuevas potencias industriales.

\section{Notas}

${ }^{1}$ Archivo Histórico Arzobispal de Guadalajara (AHAG). Sección: Gobierno; Serie: Cabildo; Sub-serie: Diezmos Jalpa; Caja 1; Años: 1794-1829. Caja 2; Años: 1830-1843.

${ }^{2} \mathrm{Al}$ ser la gravedad lo que "mueve” al agua, el punto de captación de un sistema de riego marca el punto más alto del perímetro irrigado, y el canal principal (acequia) delimita el espacio más allá del cual ya no es posible regar, delimitando el área de riego. Ver (Barceló, 1989: 25).

${ }^{3}$ Secretaría de Agricultura y Fomento, Dirección de Aguas, Departamento de Concesiones. Julio 1919.

${ }^{4}$ Ídem.

${ }^{5}$ Secretaría de Agricultura y Fomento, Dirección de Aguas, Departamento de Concesiones. Julio 1919.

${ }^{6}$ Idem.

\section{Referencias bibliográficas}

AGUIRRE ANAYA, J. A. (2011). Aprovechamiento de aguas superficiales y tecnología agroindustrial: El caso de la ex Hacienda de Jalpa, Guanajuato. En VI Encuentro Nacional para la Conservación del Patrimonio Industrial. Instituto de Ciencias Sociales y Humanidades “Alfonsa Vélez Pliego" de la BUAP, Comité mexicano para la Conservación del Patrimonio Industrial A.C. y El Museo Numismático Nacional, Puebla, México.

ALTUVE-FEBRES LORES, F. (1996). Los reinos del Perú. Apuntes sobre la monarquía peruana. Lima, Perú: Estudio Altuve-Febres y Dupuy S.C.R.L.

ALVARADO DODERO, F. H. (2017). Los conceptos virreinato y colonia en el sujeto histórico Perú. La 
segmentación de su temporalidad en la historiografía peruana, siglos XIX-XXI. (tesis de doctorado). Universidad Pablo de Olavide, Sevilla, España.

BARCELÓ, M. (1989). El diseño de espacios irrigados en Al-Ándalus: Un enunciado de principios generales. En El agua en zonas áridas: Arqueología e Historia. I Coloquio de historia y medio físico. Instituto de Estudios Almerienses. Almería, España.

BRADING, D. A. (1973). La estructura de la producción agrícola en el Bajío de 1700 a 1850. Historia Mexicana, 23(2), 197-237.

BRADING, D. A (1975). Mineros y comerciantes en el México Borbónico (1763-1810). México, D.F.: Fondo de Cultura Económica.

BRADING, D. A. (1978). Haciendas and Ranchos in the Mexican Bajio: León 1700-1860. Cambridge, Reino Unido: Cambridge University Press.

COLLADO, M. del C.. (1987). La burguesía mexicana. El emporio Braniff y su participación política, 1865-1920. México D.F.: Siglo XXI Editores.

GONZÁLEZ, L. (1980). Ciudades y Villas del Bajío colonial. Revista Relaciones, Estudios de Historia y Sociedad. Colegio de Michoacán, I(4), 100-111.

GONZÁlEZ RUBIO IRIBARREN, J. (2006). Hacienda de Jalpa de Cánovas. Jalpa, México: Fundación Jalpa.

GOYAS MEJÍA, R. y Navarro Ochoa, A.. (2013). La propiedad de la tierra en Los Altos de Jalisco durante el virreinato. Guadalajara, México: Centro Universitario de los Valles. Universidad de Guadalajara.

LEVENE, R. (1973). Las indias no eran colonias. Madrid: Espasa-Calpe, S.A.

MARTÍNEZ SALDAÑA, T. (1997). Formación y transformación de una oligarquía: el caso de Arandas, Jalisco. Guadalajara, México: Instituto Nacional de Antropología e Historia, Centro Universitario de los Altos y Universidad de Guadalajara.

MEJÍA PÉREZ CAMPOS, E. y VALENCIA CRUZ, D. (2003). El Hércules, Querétaro. Un caso de la industrialización textil del siglo XIX. En Sergio Niccolai y Humberto Morales Moreno (Coordinadores), La cultura industrial mexicana: Primer encuentro nacional de arqueología industrial. Benemérita Universidad Autónoma de Puebla y CMCPI, México.

MORIN, C. (1979). Michoacán en la Nueva España del siglo XVIII. Crecimiento y desigualdad en una economía colonial. México D.F.: Fondo de Cultura Económica.

OLIVARES NAVARRETE, M. E. (Coordinadora). (1985). Haciendas. Estado de Guanajuato. Guanajuato, México: Gobierno del Estado de Guanajuato.

OROZCO, W. L. (1895). Legislación y Jurisprudencia sobre terrenos baldíos. Tomo II. México: Imprenta de El Tiempo. Colección Digital, Universidad Autónoma de Nuevo León. Recuperado de http:// cdigital.dgb.uanl.mx/la/1080035864_C/1080035864_C.html 
ORSER, Ch. E. Jr. (2007). La promesa de una arqueología del mundo moderno en América del Sur, con especial referencia a Argentina. Revista de Arqueología Histórica Argentina y Latinoamericana. Buenos Aires. 1: 11-28.

RIONDA ARREGUIN, I. (1982). La mina de San Juan de Rayas (1670-1727). Guanajuato, México: Centro de Investigaciones Humanísticas, Escuela de Filosofía y Letras, Universidad de Guanajuato.

RIONDA ARREGUIN, l. (1985). Tesoros de la arquitectura / Testigos de la historia. Haciendas de Guanajuato. Guanajuato, México: Gobierno del Estado de Guanajuato.

RODRÍGUEZ GÓMEZ, M. G. (1984). Jalpa y San Juan de los Otates. Dos haciendas en el Bajío Colonial. Guanajuato, México: El Colegio del Bajío.

SÁNCHEZ RODRÍGUEZ, M. (2002). El granero de la Nueva España. Uso del entarquinamiento para la producción de cereales en el Bajío Mexicano. Boletín del Archivo Histórico del Agua, 7(22), 12-20.

SÁNCHEZ RODRÍGUEZ (2005). “El mejor de los títulos”. Riego, organización social y administración de recursos hidráulicos en el Bajío mexicano. Zamora, México: El Colegio de Michoacán, Gobierno del Estado de Guanajuato y Comisión Estatal del Agua.

STEWARD, J. H. (1955). Theory of Culture Change. Urbana, Illinois: University of Illinois Press.

TUTINO, J. (2016). Creando un nuevo mundo. Los orígenes del capitalismo en el Bajío y la Norteamérica española. Trad. de Mario A. Zamudio Vega. México D.F.: Fondo de Cultura Económica, Universidad Intercultural del Estado de Hidalgo y El Colegio de Michoacán.

WALLERSTEIN, I. (1979). El moderno sistema mundial. La agricultura capitalista y los orígenes de la economía-mundo europea en el siglo XVI. España: Siglo XXI Editores.

WOLF, E. R. (1972). El Bajío en el siglo XVIII. Un análisis de integración cultural. En David Barkin (compilador), Los beneficios del desarrollo regional. (pp. 63-95). México D.F.: Secretaria de Educación Pública.

Recibido: 30 de octubre de 2018

Aceptado: 21 de mayo de 2019 